\title{
The Effects of Field Independent/Field Dependent Cognitive Styles on Incidental Vocabulary Acquisition under Reading Task
}

\author{
Haiying $\mathrm{Wu}$ \\ College of Foreign Languages, Tianjin Polytechnic University, Tianjin, China
}

\begin{abstract}
The present study undertook an empirical study to investigate the effects of field independent/field dependent (FI/FD) cognitive style on incidental vocabulary acquisition from the perspective of reading task. The results show that the participants in both groups acquired the vocabulary knowledge incidentally, whether tasks were arranged or not. Besides, their FI/FD cognitive style had a significantly positive correlation with their outcomes of IVA. Moreover, when fulfilling the same tasks, the participants with FI cognitive style preference acquired relatively more vocabulary knowledge than that acquired by FD participants. The study offers some suggestions for learners in second language vocabulary building. Meanwhile, as for the pedagogical implications, language educators and teachers are informed that different cognitive style preferences must be highly considered for effective vocabulary teaching.
\end{abstract}

Index Terms - field independence, field dependence, incidental vocabulary acquisition

\section{INTRODUCTION}

Vocabulary building plays a significant role in the overall structure of the second language learning and teaching. In the field of second language vocabulary acquisition, being an increasingly popular topic, the incidental vocabulary acquisition (IVA) has aroused wide attention of researchers. Learners acquire some vocabulary knowledge unconsciously without the intention to learn through IVA. According to Laufer and Hulstijin (2001), incidental vocabulary acquisition is learning vocabulary as the by-product of any activity which is not explicitly aimed at vocabulary learning.

Based on the research of children's learning vocabulary in their native language, Nagy and Herman (1985) proposed the concept of incidental vocabulary learning. From their experimental study, they found that children do learn a large amount of vocabulary by means of incidental learning from context. A longitudinal study by Elley (1991) proved that the extensive reading may be recommended as an optimal way to enrich learners' vocabulary knowledge.

Although IVA may happen in listening, speaking, reading and writing activities, watching movies or traveling abroad, but acquiring vocabulary incidentally through reading is regarded as the major approach. Previous studies show that there are different factors influencing the outcome of IVA, such as the percentage ensuring the occurrence of IVA (Laufer, 1989), vocabulary size (Thomas Huckin \& James Coady, 1999), vocabulary learning strategy (Rubin, 1987; Li Xiaolong, 1988; Mondria \& Boer, 1991; Hulstijn, 1993). Researches have indicated that reading task have a great impact on the outcomes of IVA (Newton, 1995; Laufer \& Hulstijn, 2001). In China, Gai Shuhua (2003) designed an empirical study to investigate the outcomes of IVA, with fifty-seven English major sophomores as the subjects. The results showed that the subjects did acquire some knowledge of vocabulary incidentally, and reading task affected IVA remarkably. Meng and Chen (2015) and Ling Fang (2017) found that different types of glosses and ways of glossing had different effects on of on IVA in reading.

Field independent(FI) and Field dependent(FD) Cognitive Style

It is widely acknowledged that individual differences perform significant functions in the field of SLA. "Knowledge of learners and their characteristics" has been listed into the categories of Pedagogical Content Knowledge (PCK), a well-known concept proposed by the American educational psychologist Lee S. Shulman (1987). Oxford and Ehrman suggested that "teachers of a second language need to identify and comprehend significant individual differences in their learners if they are to provide the most effective instruction possible" (qtd. in Williams and Burden 88). It is true that learners bring many individual characteristics to the process of language acquisition and the outcomes of that process. Besides obvious factors as age, gender, motivation, aptitude and personality, another less obvious but widely studied factor relating to SLA is cognitive style. In some literatures, cognitive style and learning style are used interchangeably. "The main application of style to language learning has been through the concept of field dependence/independence (FD/FI), developed in mainstream psychology by Herman Witkin" (Skehan 237). Field independence is described as "an analytical, in contrast to a global, way of perceiving which entails a tendency to experience items as discrete from their backgrounds and reflects ability to overcome the influence of an embedding context" (qtd. in Johnson, 143). To put it another way, some people are more capable of extracting separate parts from the complex background, and these people are thought to have a tendency towards FI cognitive style, whereas the 
people who can not do this easily are believed to have preference towards FD cognitive style. (Brown, 2000) pointed out that field independence is the ability to perceive a particular, relevant item or factor in a 'field' of distracting items. In general psychological term, field may be perceptual or it may be more abstract in referring to a set of thoughts, ideas, or feelings from which your task is to perceive specific relevant subsets. FI people perceive items as discrete or unrelated to the surrounding 'field', by contrast, the people with FD style preference are easily dominated by the whole background and they are inclined to perceive things in relation to the context.

Features of FI/FD Style

There are positive and negative characteristics to both FI people and FD people. The FI people can easily concentrate on something, distinguish parts from the whole, and analyze separate parts without the disturbance of other variables. Unfortunately, too much field independent trait may also have drawbacks because FI people have more possibilities to see only the parts and details, resulting in ignoring their relationship with the whole. Compared with FI people, FD people usually perceive the whole field from a large view.

Generally speaking, persons who are more predominantly field independent tend to be more independent, competitive, and self-confident. On the contrary, field dependent individuals are more socialized and empathic, incline to derive their self-identity from persons around them, and perceptive of the feelings and thoughts of others. When faced with a situation in which decision making is necessary, the FI people are more able to separate a problem into components and focus on the components which are significant for decision making. They usually decompose a complex background into constituent elements, and then focus on, transform, and manipulate the constituents independently. In contrast, the FD people are likely to be less analytic, and they tend to perceive the situation as a whole, instead of considering it to be analyzable components. They would like to depend on external frames of reference for making judgments; therefore, they are generally thought to be sociable, extrovert and person-oriented.

It must be stressed that FD/FI style should be considered as a continuum. Although field independence and field dependence are located at the two extremes, they are not polarities, and human beings possess some of the characteristics of both FI style and FD style, showing a tendency towards one pole or the other when facing different issues. Therefore, "either pole of the style dimension is regarded as being as 'better' but instead is simply seen to suggest alternatives. Further, each pole is seen as having advantages for different tasks" (Skehan,1998).

Acquiring vocabulary incidentally by ways of reading demands the ability of focusing on unfamiliar word under the disturbance of other words, like distinguishing simple figures from complex pictures, and learners also need to restructure the information provided by reading material for the meaning of unfamiliar words in this process. Freeman \& Long (1991) hypothesized this challenge to be analogous to people learning a second language because they are needed to isolate an element from the context in which it is embedded.

Therefore, it can be summarized that there may be some internal relationship between FI/FD cognitive style and IVA. Although there were a few previous studies investigating the relevance between FI/FD style and IVA, like Cai Shengrong (2005), Tang Xia (2006), Liu Ke (2007) and Shao Lijuan (2010). However, we still know very little of the effects of FI/FD style on IVA under reading tasks. Therefore, based on previous studies and Mclaughlin's Information Processing Model, the present study makes further investigation of the effects of FI/FD cognitive style on IVA from the perspective of reading task. The whole process is illustrated as follows:

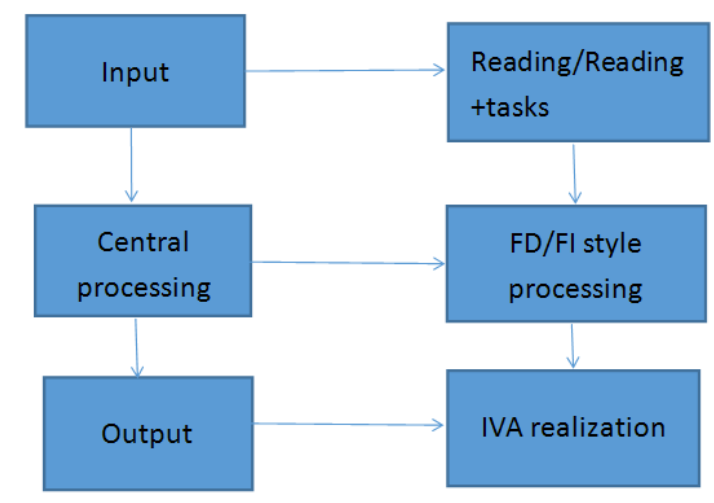

\section{RESEARCH DESIGN}

\section{Research questions}

Taking reading task as a perspective, the present study aims at the exploration to the effects of FI/FD style on IVA. Three research questions are:

1. Whether Chinese college non-English major students can acquire vocabulary incidentally in two circumstances, with reading tasks to fulfill and without any task?

2. Whether their FI/FD cognitive style preferences have any effects with their outcomes of IVA?

3. After finishing the same reading tasks, are there significant differences in outcomes of IVA between students who 
have different cognitive style preferences? If so, what kinds of difference are they?

\section{Participants Description}

The participants are one hundred and ten sophomores enrolled in two classes of Level A at Tianjin Polytechnic University. Fifty-five students of them are majoring in Information and Communication Engineering, and the rest majoring in Environmental and Chemical Engineering. For the sake of the experiment, the students majoring in Information and Communication Engineering are categorized as Group One and the other fifty-five students are categorized as Group Two, since the two groups had different treatments during the research procedure.

The participants are at the similar English proficiency because the classification in this university is based on the placement test. In Group One, during the Cognitive Style Figure Test(CSFT), three students were absent and two students didn't finish the test according to the instruction, therefore, these five students' scores in vocabulary pretest and post-test were dropped. In Group Two, three students' score for CSFT were invalid and two students were absent in pretest, therefore, there were fifty students' data were analyzed in the end.

Consequently, there are fifty participants in Group One, among them, thirty-four being males and sixteen being females. In Group Two there are fifty participants, thirty-seven being males and thirteen being females. Most of the participants acknowledged that vocabulary was of extreme significance in English learning and they did not have efficient and effective approaches in their vocabulary building.

Instruments

Four instruments employed in the present study are Cognitive Style Figure Test (CSFT), two versions of reading material (with and without reading tasks), Vocabulary Knowledge Scale (VKS).

Research Procedure

Before the main study (CSFT, pretest and post-test), a pilot study was firstly carried out. The pilot study is undertaken to find out whether the difficulty of reading material was appropriate or not and to ensure the scope target words.

CSFT was administered to the participants to assess their FI/FD cognitive styles. Their performances in part one were used as references to decide whether he of she understood the requirements or not. There were fifty and fifty-three valid papers in Group One and Group Two respectively for date analysis. The full score of CSFT is twenty-four, and the higher they scored in CSFT, the more FI tendency he or she had, and vice versa.

Since the third research question is whether there are any differences in outcomes of IVA between students who have different cognitive style preferences after finishing the same reading tasks, it is necessary to make a distinction between FI students and FD students. It should be stressed that this distinction does not mean either type of cognitive style is better of worse than another, it is just a research design for the sake of the present study.

To explore the third research question, fifty students' scores of CSFT in Group Two were used as the references to make distinction between FI students and FD students. According to quartile frequency statistics for the scores of CSFT, the participants with the score below 19.250 fall into FD Group, and the participants with the score higher than 22.500 fall into FI Group, and the rest participants whose scores in CSFT between the two are not concerned for this research question.

In the pretest, all the participants were told their performances in this vocabulary test would not be recorded for any academic achievements, but to gather information about their vocabulary size. Fifty-five students in Group One and fifty-three students in Group Two were pre-tested by using a vocabulary test of twenty words which were composed of ten target words they would come across in the reading material and another ten words they had learned in their textbook.Their vocabulary knowledge of the twenty words was tested by VKS within twenty minutes.

The treatment and post-test were conducted three days after pretest. The participants in Group One were presented with the reading passage alone without any task to fulfill. They were given enough time to ensure their complete understanding of this passage. About sixteen minutes later the reading materials were turned back. The vocabulary post-test proceeded immediately after the treatment. The participants' knowledge of the ten target words were measured by VKS. The vocabulary post-test lasted fifteen minutes. Their papers were collected and scored in the same way in the pretest.

The participants in Group Two were presented with the reading passage and the tasks which they had to finish after reading, including eight statements' judgment and ten blanks filling tasks. It took thirty-five minutes. All the reading materials were turned back and the vocabulary post-test was conducted immediately. The vocabulary post-test papers and the ways of scoring of Group Two were the same way as in Group One. It should be mentioned that during all the process of treatment and vocabulary tests no dictionaries and discussions were allowed for two groups.

Data Collection

The choices of the items in CSFT, pretest and post-test were turned into scores. The full scores of CSFT are twenty-four. The higher the score is, the more FI tendency he or she has. For pretest, the full scores are one hundred. Since there are ten words served as distracts in the pretest, it is the scores of ten target words that were used for data analysis. Consequently, the full scores are fifty for both the pretest and post-test.

The raw data of the three parts for each participant were put into computer and analyzed with the SPSS 17.0 statistics software package. The descriptive analysis of CSFT and IVA, and the inferential analysis between FI/FD cognitive style and IVA were carried out by SPSS 17.0. 


\section{DATA Presentation AND Discussion}

\section{Descriptive Data Presentation}

The descriptive statistics of CSFT, the vocabulary pretest and vocabulary post-test of the two groups are showed in this section.

TABLE 1

GROUP ONE'S SCORES IN CSFT

\begin{tabular}{|l|l|l|l|l|l|}
\hline & $\mathrm{N}$ & Minimum & Maximum & Mean & Std. Deviation \\
\hline the scores of CSFT & 50 & 15.0 & 24.0 & 20.430 & 2.7866 \\
Valid N (listwise) & 50 & & & & \\
\hline
\end{tabular}

Note: full score is twenty-four for CSFT

TABLE 2

GROUP TWO'S SCORES IN CSFT

\begin{tabular}{|l|l|l|l|l|l|}
\hline & N & Minimum & Maximum & Mean & Std. Deviation \\
\hline the scores of CSFT & 50 & 15.0 & 24.0 & 20.470 & 2.5583 \\
Valid N (listwise) & 50 & & & & \\
\hline
\end{tabular}

As is showed in table 1 and table 2, there are fifty valid CSFT scores in both Group One and Group Two. The minimum and maximum for two groups are fifteen and twenty-four respectively. The mean for Group One is 20.430 with the standard deviation being 2.7866 and the mean for Group Two is 20.470 with the standard deviation being 2.5583. Eight participants in Group One and seven participants in Group Two get full scores, however, some participants in both groups only get fifteen, which means participants show relatively different cognitive style tendency.

According to Song Heyi (1988), the mean of CSFT for high school students was 13.17. In the present study, the mean of Group One and Group Two are 20.430 and 20.470 respectively, which indicates the participants have more tendencies towards FI cognitive style. Most participants' scores in CSFT are around twenty-one. This result is consistent with Witkin's opinion that adults tend to be more field independent than children. In addition, the participants of two groups are both science majors; therefore it is reasonable that more FI cognitive style tendency had been showed, and this result corresponds with Clark, Seat and Weber's (2000) findings.

TABLE 3

GROUP ONE'S SCORES IN VOCABULARY PRETEST, POST-TEST AND VOCABULARY GROWTH

\begin{tabular}{|c|c|c|c|c|c|}
\hline & $\mathrm{N}$ & Minimum & Maximum & Mean & Std. Deviation \\
\hline pretest & 50 & 11 & 22 & 15.16 & 2.972 \\
\hline post-test & 50 & 18 & 30 & 23.26 & 3.148 \\
\hline vocabulary growth & 50 & 3 & 14 & 8.10 & 2.509 \\
\hline Valid N (listwise) & 50 & & & & \\
\hline
\end{tabular}

Note: full score of pretest and post-test are 50

Table 3 is the overall presentation of the scores in vocabulary pretest, post-test and vocabulary growth of Group One. Fifty participants' scores are valid. The minimum and maximum of target words in pretest are eleven and twenty-two respectively with the mean being 15.16 and standard deviation 2.972 . These results reveal the fact that most of the participants chose the option of A or B of the VKS in the pretest, which means they had not seen targets words before or they had little knowledge of the target words. Based on this fact, the vocabulary's improvement in the post-test can be attributed to the reading treatment to a great extent, rather than the vocabulary knowledge they had acquired before.

In post-test, the minimum is eighteen and maximum is thirty, with the mean being 23.26 and standard deviation 3.148 . Compared with the scores in pretest, a quantitatively small but statistically significant amount of vocabulary has been acquired after the reading treatment. The maximum of vocabulary growth after the treatment is fourteen with the mean of 8.10 and standard deviation of 2.509. Given that more reading materials including the target words and more exposure frequency are provide to participants, more significant amount of vocabulary are supposed to be acquired.

Since the participants in Group Two are required to finish two tasks after the same reading treatment, in consequence, it is believed that, compared with Group One, Group Two need more workload to process reading material and have more opportunity to access to the target words. The descriptive data for Group Two are showed in table 4. 
TABLE 4

GROUP TWO'S SCORES IN VOCABULARY PRETEST, POST-TEST AND VOCABULARY GROWTH

\begin{tabular}{|l|l|l|l|l|l|}
\hline & N & Minimum & Maximum & Mean & Std. Deviation \\
\hline pretest & 50 & 10 & 22 & 15.98 & 2.386 \\
post-test & 50 & 23 & 39 & 31.48 & 3.333 \\
vocabulary growth & 50 & 9 & 20 & 15.50 & 2.188 \\
Valid N (listwise) & 50 & & & \\
\hline
\end{tabular}

Table 4 gives the full presentation of the descriptive data of Group Two. There are fifty participants' scores being valid. In the pretest, with the mean being 15.98, the minimum and maximum are ten and twenty-two respectively, which are almost the same as that of Group One. However, compared with Group One, a great advancement can be found in the vocabulary post-test of Group Two. The minimum is twenty-three and maximum is thirty-nine, with the mean being 31.48 and standard deviation of 3.333. In terms of vocabulary growth, a more significant amount of vocabulary growth is achieved by Group Two than that by Group One. From the perspective of mean, more than seven vocabulary are acquired by Group Two than Group One, with the minimum being nine and maximum being twenty, which are both higher than that of Group One.

From the descriptive data presentation in table 3 and table 4 , it can be summarized that both groups make improvement in vocabulary post-test, and Group Two's improvement is much higher than Group One. It can be interpreted from the perspective of task, since two tasks are arranged to Group Two and no task to Group One, in consequence, more information restructuring ability is required for Group Two.

Paired Samples T-tests

To investigate whether Chinese college non-English major students can acquire vocabulary incidentally in two circumstances, with reading tasks and without any task, paired samples T-tests are conducted between vocabulary pretest and post-test for both Group One and Group Two. The results for Group One are presented in table 5, table6 and table 7 respectively.

TABLE 5

PAIRED SAMPLES STATISTICS FOR GROUP ONE

\begin{tabular}{|ll|l|l|l|l|}
\hline & & Mean & N & Std. Deviation & Std. Error Mean \\
\hline Pair 1 & the scores of vocabulary in pretest & 15.16 & 50 & 2.972 & .420 \\
& the scores of vocabulary in post-test & 23.26 & 50 & 3.148 & .445 \\
\hline
\end{tabular}

As is shown in table 5, the mean of the participants' vocabulary knowledge of ten target words in the pretest is 15.16 , while the mean in the post-test is 23.26 , which indicates a quantitative improvement in the acquisition of the target words after the treatment. To make further exploration about whether there is any significant difference of the ten target words between pretest and post-test, the tables of paired samples correlations and paired samples T-test are presented below.

TABLE 6

PAIRED SAMPLES CORRELATIONS FOR GROUP ONE

\begin{tabular}{|ll|l|l|l|}
\hline & & $\mathrm{N}$ & Correlation & Sig. \\
\hline Pair 1 & $\begin{array}{l}\text { the scores of vocabulary in pretest \& } \\
\text { the scores of vocabulary in post-test }\end{array}$ & 50 & .665 & .000 \\
\hline
\end{tabular}

Table 6 show the relationship between the two variables, the scores of vocabulary in pretest and post-test, the coefficient of which is .665 , with the Sig. (2-tailed) being $.000(<0.05)$. These results prove the participants' knowledge in the pretest is significantly different from that in the post-test. The negative $t$ value in table 7 indicates that the mean of vocabulary in pretest is less than that in post-test. In another word, the participants do acquire some knowledge of vocabulary incidentally in the reading treatment.

TABLE 7

PAIRED SAMPLES T-TEST FOR GROUP ONE

\begin{tabular}{|c|c|c|c|c|c|c|c|c|c|}
\hline & & \multicolumn{5}{|c|}{ Paired Differences } & \multirow[b]{3}{*}{$\mathrm{t}$} & \multirow[b]{3}{*}{ df } & \multirow[b]{3}{*}{ Sig. (2-tailed) } \\
\hline & & \multirow[b]{2}{*}{ Mean } & \multirow{2}{*}{$\begin{array}{l}\text { Std. } \\
\text { Deviation }\end{array}$} & \multirow{2}{*}{$\begin{array}{l}\text { Std. } \\
\text { Error } \\
\text { Mean }\end{array}$} & \multicolumn{2}{|c|}{$\begin{array}{l}95 \% \text { Confidence Interval of } \\
\text { the Difference }\end{array}$} & & & \\
\hline & & & & & Lower & Upper & & & \\
\hline Pair 1 & $\begin{array}{l}\text { the scores of vocabulary } \\
\text { in pretest - the scores of } \\
\text { vocabulary in post-test }\end{array}$ & -8.100 & 2.509 & .355 & -8.813 & -7.387 & -22.827 & 49 & .000 \\
\hline
\end{tabular}


The same statistic method is used to see the results of Group Two which are illustrated in table 8, table 9 and table 10 respectively below.

TABLE 8

PAIRED SAMPLES STATISTICS FOR GROUP TWO

\begin{tabular}{|ll|l|l|l|l|}
\hline & & Mean & N & Std. Deviation & Std. Error Mean \\
\hline Pair 1 & the scores of vocabulary in pretest & 15.98 & 50 & 2.386 & .337 \\
& the scores of vocabulary in post-test & 31.48 & 50 & 3.333 & .471 \\
\hline
\end{tabular}

As can be seen in table 8, the mean vocabulary knowledge of Group Two's in pretest is 15.98 which is nearly the same as that of Group One. While the mean in the post-test for Group Two is 31.48 which is significantly higher than that in the pretest. These results suggest a quantitative improvement in the acquisition of the target words after the treatment. Tables of paired samples correlations and paired samples T-test for Group Two are presented below to make further investigation about whether there is any significant difference of the ten target words between pretest and post-test.

TABLE 9

PAIRED SAMPLES CORRELATIONS FOR GROUP TWO

\begin{tabular}{|ll|l|l|l|}
\hline & \multicolumn{1}{|c|}{ N } & Correlation & Sig. \\
\hline Pair 1 & $\begin{array}{l}\text { the scores of vocabulary in pretest \& } \\
\text { the scores of vocabulary in post-test }\end{array}$ & 50 & .756 & .000 \\
\hline
\end{tabular}

TABLE 10

PAIRED SAMPLES T-TEST FOR GROUP TWO

\begin{tabular}{|c|c|c|c|c|c|c|c|c|c|}
\hline & & \multicolumn{5}{|c|}{ Paired Differences } & \multirow[b]{3}{*}{$\mathrm{t}$} & \multirow[b]{3}{*}{ df } & \multirow{3}{*}{$\begin{array}{l}\text { Sig. } \\
\text { (2-tailed) }\end{array}$} \\
\hline & & \multirow[b]{2}{*}{ Mean } & \multirow{2}{*}{\begin{tabular}{|l} 
Std. \\
Deviation
\end{tabular}} & \multirow{2}{*}{$\begin{array}{l}\text { Std. Error } \\
\text { Mean }\end{array}$} & \multicolumn{2}{|c|}{$\begin{array}{l}95 \% \text { Confidence Interval } \\
\text { of the Difference }\end{array}$} & & & \\
\hline & & & & & Lower & Upper & & & \\
\hline Pair 1 & $\begin{array}{l}\text { the scores of vocabulary in } \\
\text { pretest - the scores of } \\
\text { vocabulary in post-test }\end{array}$ & -15.500 & 2.188 & .309 & -16.122 & -14.878 & -50.101 & 49 & .000 \\
\hline
\end{tabular}

Table 9 shows the relationship of the two variables, the scores of vocabulary in pretest and post-test of Group Two, the coefficient of which is .756 , with the Sig. (2-tailed) being $.000(<0.05)$. These results prove the participants' knowledge in the pretest is significantly different from that in the post-test. To put it another way, they do acquire some knowledge of target words incidentally after the treatment. The negative $t$ value in table 10 indicates that the mean vocabulary in pretest is less than that in post-test. Comparison can be made between the $t$ value of Group One and Group Two, and it is clear that more vocabulary knowledge are acquired incidentally by Group Two than that by Group One.

By now, the descriptive analysis of two groups' results and paired sample T-tests have provided an answer to the first research question. Chinese college non-English major students can acquire some vocabulary knowledge incidentally through reading, whether tasks are arranged or not. Besides, through the comparison, the participants who have to finish tasks after reading perform better in IVA than those participants with no task to fulfill.

Correlation Analysis

Being one of the most important research questions, Pearson correlations are conducted to answer whether the participants' cognitive style preferences have any effects on their outcomes of IVA. According to the definition in statistics, if the absolute value of the coefficient is between 0.40 and 0.70 , it can be said that a relatively significant correlation is between the two variables. Table 11 and table 12 serve as the presentation of Pearson correlation analyses for Group One and Group Two.

TABLE 11

CORRELATIONS BETWEEN FI/FD COGNITIVE STYLE AND IVA FOR GROUP ONE

\begin{tabular}{|ll|l|l|}
\hline \multicolumn{1}{|l|}{} & the scores of CSFT & the vocabulary growth \\
\hline the scores of CSFT & Pearson Correlation & 1 & $.592^{* *}$ \\
& Sig. (2-tailed) & 50 & .000 \\
& $\mathrm{~N}$ & 50 \\
\hline the vocabulary growth & Pearson Correlation & $.592^{* *}$ & 1 \\
& Sig. (2-tailed) & .000 & 50 \\
& $\mathrm{~N}$ & 50 & 50 \\
\hline
\end{tabular}


TABLE 12

CORRELATIONS BETWEEN FI/FD COGNITIVE STYLE AND IVA FOR GROUP TWO

\begin{tabular}{|ll|l|l|}
\hline & the scores of CSFT & the vocabulary growth \\
\hline the scores of CSFT & Pearson Correlation & 1 & $.479^{* *}$ \\
& Sig. (2-tailed) & 50 & .000 \\
& $\mathrm{~N}$ & 50 \\
\hline the vocabulary growth & Pearson Correlation & $479^{* *}$ & 1 \\
& Sig. (2-tailed) & .000 & \\
$\mathrm{~N}$ & 50 & 50 \\
\hline
\end{tabular}

As can be seen from table 11 and table 12, the participants' FI/FD cognitive style correlates to some extent with their vocabulary growth, namely IVA. For Group One, the correlation between FI/FD cognitive style and IVA is positive and relatively significant $(\mathrm{r}=.592 * *, \mathrm{p}<0.01)$. For Group Two, a relatively significant positive correlation between FI/FD cognitive style and IVA can be found as well $\left(\mathrm{r}=.479^{* *}, \mathrm{p}<0.01\right)$. The results show that the more FI tendency a participant has, the more vocabulary knowledge can be acquired incidentally.

By now, the second research question has been answered through the consequences of Pearson correlation analysis. The participants' FI/FD cognitive style preferences have a positive and significant correlation with the outcome of IVA.

Independent Sample T-test

The third research question concerns with whether there are significant differences in outcomes of IVA between students who have different cognitive style preferences after finishing the same reading tasks. Therefore, it is necessary to make a distinction between FI participants and FD participants, which doesn't mean the priority of FI cognitive style to FD cognitive style, or vice versa. This distinction is just for the convenience to explore the answer to the research question for the present study. Since no task is arranged for Group One, it is believed that more workload and information processing are involved in for Group Two. Consequently, it is Group Two's CSFT scores that serve as the data sources of the third research question.

The quartile frequency analysis is used to divide CSFT scores of FI group and FD group in this study, since there is no common criterion used to distinguish the scores between FI style and FD style. According to table 13, the participants with the scores lower than 19.250 fall into the FD group and the participants with the scores higher than 22.500 are in FI group. Therefore, based on the statistics in table 13 and table 14, twelve participants are grouped in FD and eleven participants in FI.

TABLE 13

QUARTILE FREQUENCY STATISTICS FOR FI/FD OF GROUP TWO

\begin{tabular}{|ll|l|}
\hline N & Valid & 50 \\
& Missing & 0 \\
Minimum & & 15.0 \\
Maximum & & 24.0 \\
Percentiles & 25 & 19.250 \\
& 50 & 21.000 \\
& 75 & 22.500 \\
\hline
\end{tabular}


TABLE 14

CSFT SCORES FREQUENCY OF GROUP TWO

\begin{tabular}{|c|c|c|c|c|c|}
\hline & & Frequency & Percent & Valid Percent & Cumulative Percent \\
\hline \multirow[t]{11}{*}{ Valid } & 15.0 & 4 & 8.0 & 8.0 & 8.0 \\
\hline & 17.0 & 3 & 6.0 & 6.0 & 14.0 \\
\hline & 18.0 & 1 & 2.0 & 2.0 & 16.0 \\
\hline & 18.5 & 4 & 8.0 & 8.0 & 24.0 \\
\hline & 19.5 & 6 & 12.0 & 12.0 & 36.0 \\
\hline & 20.0 & 5 & 10.0 & 10.0 & 46.0 \\
\hline & 21.0 & 11 & 22.0 & 22.0 & 68.0 \\
\hline & 22.5 & 5 & 10.0 & 10.0 & 78.0 \\
\hline & 23.0 & 4 & 8.0 & 8.0 & 86.0 \\
\hline & 24.0 & 7 & 14.0 & 14.0 & 100.0 \\
\hline & Total & 50 & 100.0 & 100.0 & \\
\hline
\end{tabular}

Independent sample T-test is conducted to make further investigation about the different outcomes of IVA between the participants of Group FI and Group FD. The descriptive data for the two groups in the outcome of IVA are reported in table 15 .

TABLE 15

DESCRIPTIVE DATA FOR GROUP FI AND GROUP FD IN THE OUTCOME OF IVA

\begin{tabular}{|ll|l|l|l|l|}
\hline & Group & $\mathrm{N}$ & Mean & Std. Deviation & Std. Error Mean \\
\hline the outcome of IVA & FI & 11 & 17.64 & 1.748 & .527 \\
& FD & 12 & 14.42 & 1.505 & .434 \\
\hline
\end{tabular}

As can be seen from table15, there are eleven and twelve participants for Group FI and Group FD respectively. The mean for Group FI is 17.64 and for Group FD is 14.42, which means the quantitatively significant difference in the outcomes of IVA. The two groups have almost the similar standard deviation being 1.748 and 1.505 , and the two relatively low value means there is no much difference in Group FI and Group FD respectively. Although there is more vocabulary acquired by Group FI than by Group FD in terms of mean, whether the results are meaningful statistically, the table 16 of the independent sample T-test is necessary and illustrated below.

TABLE 16

INDEPENDENT SAMPLE T-TEST

\begin{tabular}{|c|c|c|c|c|c|c|c|c|c|c|}
\hline & & \multicolumn{2}{|c|}{$\begin{array}{l}\text { Levene's Test } \\
\text { for Equality of } \\
\text { Variances }\end{array}$} & \multicolumn{7}{|c|}{ t-test for Equality of Means } \\
\hline & & \multirow[b]{2}{*}{$\mathrm{F}$} & \multirow[b]{2}{*}{ Sig. } & & & & & & $\begin{array}{l}95 \% \mathrm{Cc} \\
\text { of the D }\end{array}$ & $\begin{array}{l}\text { nce Interval } \\
\text { nce }\end{array}$ \\
\hline & & & & $\mathrm{t}$ & df & $\begin{array}{l}\text { Sig. } \\
\text { (2-tailed) }\end{array}$ & $\begin{array}{l}\text { Mean } \\
\text { Difference }\end{array}$ & $\begin{array}{l}\text { Std. Error } \\
\text { Difference }\end{array}$ & Lower & Upper \\
\hline \multirow{2}{*}{$\begin{array}{l}\text { the } \\
\text { outcome of } \\
\text { IVA }\end{array}$} & $\begin{array}{l}\text { Equal variances } \\
\text { assumed }\end{array}$ & \multirow[t]{2}{*}{136} & \multirow[t]{2}{*}{.716} & 4.746 & 21 & .000 & 3.220 & .678 & 1.809 & 4.630 \\
\hline & $\begin{array}{l}\text { Equal variances } \\
\text { not assumed }\end{array}$ & & & 4.714 & 19.870 & .000 & 3.220 & .683 & 1.794 & 4.645 \\
\hline
\end{tabular}

From table 16, the Sig. of Levene's Test for Equality of Variances is .716 (>0.05), which means the equal variance of the two groups. Therefore, the data in Equal variances assumed are used to be the results in Independent sample T-test. From this table, the positive value of Mean Difference between Group FI and Group FD is 3.220 which indicates that three more words were acquired incidentally by Group FI than Group FD. The standard error difference is 0.678 and the $\mathrm{t}$ value is 4.746. The Sig. (2-tailed) equals to .000 , which is less than 0.05 . That proves that there are significant differences in the outcomes of IVA between FI cognitive style and FD cognitive style.

By now, the third research question has been supported by the positive answer, that there are significant differences in outcomes of IVA between students who have different cognitive style preferences after finishing the same tasks. The students with FI cognitive style preference acquired more vocabulary knowledge incidentally to some extent than those with FD cognitive style preference. 


\section{CONCLUSION}

The major findings of the present study will be summarized as the answers to the three research questions at the beginning of the paper. Firstly, the mean of vocabulary growth for two groups are 8.10 and 15.5 respectively, which means quantitatively significant that vocabulary have been acquired after the reading treatment. Therefore, extensive reading can serve as the reliable source of intermediate Chinese EFL learners' vocabulary building. Secondly, the participants' cognitive style preferences have a relatively significant positive correlation with their outcomes of IVA. Thirdly, there are significant differences in outcomes of IVA between the students with FI cognitive style and FD cognitive style after finishing the same reading tasks. Learners with higher FI cognitive style tendency are more likely to acquire more vocabulary knowledge than those with FD cognitive style tendency after finishing the same tasks.

\section{ACKNOWLEDGMENTS}

The author acknowledges financial support from China Tianjin Philosophy and Social Science Project (TJWW15-019). Thanks also go to Lan Peili for her great ideas and generous support.

\section{REFERENCES}

[1] Brown, H. D. (2000). Principals of Language Learning and Teaching. Beijing: Foreign Language Teaching and Research Press.

[2] Cai Shengrong. (2005). Relationship between Cognitive Style and Incidental Vocabulary Acquisition. M.A. Thesis. Beijing Normal University.

[3] Clark, S., Seat, E. and Weber, F. (2000). The performance of engineering students on the group embedded figures test. Proceedings, 30th ASEE/IEEE Frontiers in Education Conference. Kansas City, MO. Available. https://www.researchgate.net/publication/3883280_The_Performance_Of_Engineering_Students_On_The_Group_Embedded_ Figures_Test. (accessed 24/2/2018).

[4] Elley, R. Day. (1991). The Benefits of $\quad$ Extensive Reading. http://www.oup-boodworms.com/downloads/pdf/successful/er-article.pdf. (accessed 1/2/2018).

[5] Gai Shuhua. (2003). An Empirical Study on Incidental Vocabulary Acquisition of English Major College Students. Foreign Language Teaching and Research, 4, 282-286.

[6] Hulstijn, J. (1992). Retention of inferred and given word meanings: Experiments in incidental vocabulary learning. In P. Arnaud and H. Bejoint (Eds.) Vocabulary and Applied Linguistics. London: Macmillan, 113-125.

[7] Johnson, K. (2002). An Introduction to Foreign Language Learning and Teaching. Beijing: Foreign Language Teaching and Research Press.

[8] Larsen-Freeman, D. \& Long M.(1991). An introduction to second language acquisition and research. London: Longman. Foreign Language Teaching and Research Press.

[9] Laufer, B. (1989). What percentage of text is essential for comprehension? Special Language; from Humans Thinking to Thinking Machines. Clevedon: Multilingual Matters, 316-323.

[10] Laufer, B. \& Hulstijn, J.H. (2001). Incidental vocabulary acquisition in a second language: The construct of task-induced involvement load. Applied Linguistics, 22, 11-26.

[11] Lee S. Shulman. (1987). Knowledge and Teaching: Foundations of the New Reform. Harvard Educational Review, 57, 7-9.

[12] Li Xiaolong. (1988). Effects of contextual cues on inferring and remembering meanings of new words. Applied Linguistics, 9,401-413.

[13] Ling Fang. (2017). The Effect of Different Types of Glosses on Incidental Vocabulary Acquisition in Reading. M.A. Thesis. Si Chuan International Studies University.

[14] Liu Ke. (2007). An Empirical Study of the Relationship between Cognitive Style and Incidental Vocabulary Acquisition. M.A. Thesis. Henan University of Science and Technology.

[15] Meng Chunguo \& Chen Lipeng. (2015). The Effects of Glossing on Timed Comprehension and Incidental Vocabulary Acquisition. Foreign Languages and Their Teaching, 1, 50-54.

[16] Mondria, J. \& Wit-De Boer, M.(1991). Guessability and the retention of words in a foreign language. Applied Linguistics, 12, 249-263.

[17] Muriel Saville Troike. (2006). Introducing Second Language Acquisition. Cambridge: Cambridge University Press.

[18] Nagy, W. \& Herman, P. (1985). Incidental vs. instructional approaches to increasing reading vocabulary. Educational Perspectives, 23, 16-21.

[19] Newton, J. (1995). Task-based interaction and incidental vocabulary learning: A case study. Second Language Research, 11, 159-177.

[20] Rubin, J. (1987). Learner strategies: Theoretical assumptions, research history and typology. Learner Strategies in Language Learning. New York: Prentice Hall, 15-30.

[21] Shao Lijuan. (2010). The Study on Incidental Vocabulary Acquisition under the Influence of Two Types of Cognitive Styles. M.A. Thesis. Xibei Normal University.

[22] Skehan, P. A. (1998). Cognitive Approach to Language Learning. Shanghai: Shanghai Foreign Language Research Press, 237.

[23] Song Heyi. (1988). An Account on Compilating and Revising of Cognitive Style Figure Test. In Xie Sijun \& Zhang Houcan (eds.), Cognitive style -- An Experimental Study of the Latitude of Personality. Beijing: Beijing Normal University Press, 261-277.

[24] Tang Xia. (2006). The Relationship Between College Students' Cognitive Styles and Incidental Vocabulary Acquisition. M.A. Thesis. Shandong University.

[25] Thomas H and James C. (1999). Incidental Vocabulary Acquisition in a Second Language. Cambridge: Cambridge University Press. 
[26] Williams, M and Burden, R.L. (1997). Psychology for Language Teachers. Cambridge: Cambridge University Press, 88.

Haiying Wu was born in Shandong province, China. She completed a Doctor's degree in linguistics and applied linguistics in Minzu University of China. She got a Master's degree in English language and literature in Shandong Normal University, China. She has been teaching English as a full-time associate professor for 14 years. Her main research interests are studies of language and culture, academic teaching and studies and the application of Chaos theory in linguistic studies. She has published: Wu Haiying. (2016). The Cultural Cognition of Numeral Metaphor in English and Chinese. Guangzhou: World Publishing Corporation, Guangdong Branch. She also published more than 10 papers in linguistic journals. Wu Haiying is currently teaching in foreign languages college, Tianjin Polytechnic University, China. 